\section{Brain, Behavior and Evolution}

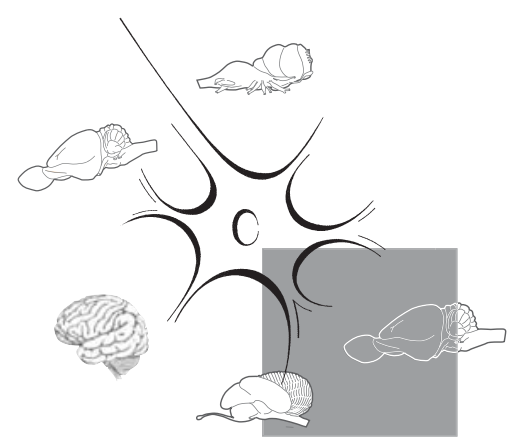

The scaling of vertebrate (particularly mammalian and avian) brain size relative to body mass has received much attention and its precise nature has been the subject of long-standing debate [Jerison, 1973; van Dongen, 1998; Weisbecker and Goswami, 2011]. Virtually all studies of vertebrate brain size evolution are conducted in the framework of assessing brain size relative to body mass [but see Deaner et al., 2007], mostly through the use of brain size residuals on a logarithmic regression of brain size against body mass.

While body mass data are essential for the meaningful analysis of brain size, the choice of an appropriate proxy of body mass is not straightforward. Two avenues, each with their merits, have been used in the past: first, the recording of body mass along with brain measurement of specimens, and second, the use of literaturebased mass averages. The fact that brain size/body mass scaling differs within as well as between species [e.g. Kruska, 2005] might suggest that the use of individualbased brain sizes would give greater precision. However, it can also be argued that the use of literature-based body mass better acknowledges the error inherent to the use of a single species value, as it represents the statistical mean of a species-specific 'cloud' of data points. In most cases, the difference between literature averages and individual

\title{
An Improved Body Mass Dataset for the Study of Marsupial Brain Size Evolution
}

\author{
Vera Weisbecker $^{a}$ Ken Ashwell $^{b}$ Diana Fisher ${ }^{a}$ \\ a School of Biological Sciences, University of Queensland, Brisbane, Qld., and \\ ${ }^{b}$ Department of Anatomy, School of Medical Sciences, University of New South Wales, \\ Sydney, N.S.W., Australia
}

data is expected to be small, as the brain sizes of several adult specimens and their body masses are typically recorded, and thus the body mass range of individualbased body mass data is expected to approximate that of the averages of the literature. It is therefore not surprising that studies of body mass versus brain sizes have successfully used both literature-based [Isler and Van Schaik, 2009] and individual-based body mass data [e.g. Eisenberg and Wilson, 1981].

In a recent study on marsupial endocranial volumes (considered to proxy brain weight), Ashwell [2008] preferred the use of individual body mass data which were, however, mostly unavailable from museum collections. Instead, he estimated individual body mass based on a frequently used body mass estimation formula specifically for marsupials, which is based on mandible length [Myers, 2001]. In this note, we point out that although many of the body mass estimates from Ashwell [2008] provide a good fit to individual museum records, there are some issues that suggest to us that body mass averages from the literature reflect specimen body mass more accurately. In particular, mandibular length estimates appear to have underestimated body mass in many species, particularly those with a feeding ecology that favours short snouts. In a few instances, the body masses of com- paratively long-snouted species appeared overestimated. For example, the mandiblebased estimate for the very short-snouted tree kangaroo Dendrolagus matschiei is just over $4 \mathrm{~kg}$, but its average adult weight is $8.8 \mathrm{~kg}$. On the other end of the spectrum, the literature-based body mass values of the long-nosed bandicoot genus Perameles exceed the mandible-based estimates by between 30 and 100\%. We therefore consider literature-based body mass values as more appropriate and in this note provide a new dataset of body mass collected from the literature to accompany the endocranial volumes from Ashwell [2008].

Online supplementary table 1 (see www.karger.com/doi/10.1159/000348647 for all online suppl. material) lists the species investigated by Ashwell [2008], together with our new body mass dataset for males, females and averaged weights from the literature as well as the body mass data based on Ashwell's 2008 mandible-based measurements. Literature data on the different sexes are presented because it can be argued that female body masses are more informative in marsupials, as male masses are highly variable due to strong sexual dimorphism [Fisher and Owens, 2000; Fisher and Cockburn, 2006] and indeterminate growth in some clades [Cockburn and Johnson, 1988]. Furthermore, brain size analyses involving life history traits often

\section{KARGER}

E-Mail karger@karger.com

www.karger.com/bbe
(C) 2013 S. Karger AG, Basel

0006-8977/13/0822-0081\$38.00/0
Vera Weisbecker

School of Biological Sciences, University of Queensland

8 Goddard Building, Room 347

St. Lucia/Brisbane, QLD 4072 (Australia)

E-Mail v.weisbecker@uq.edu.au 
involve variables of female investment (e.g. litter size, gestation period and age to weaning [Weisbecker and Goswami, 2010]) for which it might be preferable to use female-only weights. References for all body mass values are listed in the online supplementary table 2 .

Only seven very rare species from Papua-New Guinea had to be omitted due to the entire lack of body mass data [including Murexia melanurus (formerly Antechinus wilhelmina), Dasyurus spartacus, Rhynchomeles prattorum, Spilocuscus krameri, Strigocuscus pelengensis and Phalanger rothschildi], and it might in this case be preferable to use the estimated value. In addition, four species were removed as they represented junior synonyms or subspecies (Trichosurus fuliginosus is T. vulpecula, Petrogale venusta is $P$. brachyotis, $P$. intercastellanus is P. mimicus and Petaurus biacensis is a subspecies of $P$. breviceps) and their endocranial volumes were united with those of the species with the senior synonym. Furthermore, two $P$. orientalis specimens were united into one entry with volumes averaged. Lastly, the brain volume value for Dendrolagus bennettianus was corrected to include only one adult speci- men (the others being deemed juvenile by the curator of the Australian Museum).

Comparing brain size/body mass regression coefficients and intercepts using mandible-based data, female-only data and average data show differences in intercept, but not scaling. The log10-based brain size/ body mass scaling formulae are:

Brain volume $=0.653 \pm 0.0078 x-1.13$ \pm 0.023 (mandible-based body mass estimates)

Brain volume $=0.656 \pm 0.009 \mathrm{x}-1.187$ \pm 0.027 (body mass averages)

Brain volume $=0.0658 \pm 0.009 x-0.165$ \pm 0.027 (female body mass)

An ANCOVA revealed no significant differences in slope between the three regressions ( $p=0.904)$ but differences in intercept $(\mathrm{p}=0.000)$ between the regressions. A Tukey test revealed that this result relates to the lower intercept of the averaged body mass regression versus the mandible-based body mass regression $(\mathrm{p}=0.000)$. The lower intercept of the female body mass-based regression relative to the mandible-based body mass regression is also near-significant ( $p=0.0563)$. In other words, mandible-based and literature-based body mass values scale the same with brain size. How- ever, by consistently underestimating body mass, mandible-based estimates make marsupial brains appear, on average, larger than they are relative to body mass. An example in absolute terms is that the formulae based on mandible length, female masses and average masses estimate the brain size of a 500-gram marsupial at 4.3, 4.1 and $3.8 \mathrm{ml}$, respectively. This corresponds to a maximum of just over $10 \%$ difference, which is mostly within the intraspecific range of species for which Ashwell [2008] had larger specimen numbers available. Nevertheless, given the significant differences particularly with regards to mandible-based versus average body size-based measurements, we propose that the use of literature-based body mass values is more appropriate for future analyses of brain size evolution in marsupials.

\section{Acknowledgements}

V.W. was supported by Discovery Early Career Researcher Grant No. DE120102034 from the Australian Research Council. D.O.F. was supported by an ARC Fellowship (FTll0100191).

\section{References}

-Ashwell K (2008): Encephalisation of Australian and New Guinean marsupials. Brain Behav Evol 71:181-199.

Cockburn A, Johnson CN (1988): Patterns of growth; in Tyndale-Biscoe $\mathrm{CH}$, Janssens PA (eds): The Developing Marsupial. Berlin, Springer, pp 28-40.

-Deaner R, Isler K, Burkart J, van Schaik C (2007): Overall brain size, and not encephalization quotient, best predicts cognitive ability across non-human primates. Brain Behav Evol 70: 115-124.

- Eisenberg JF, Wilson DE (1981): Relative brain size and demographic strategies in didelphid marsupials. Am Nat 118:1-15.
Fisher DO, Cockburn A (2006): The large-male advantage in brown antechinuses: female choice, male dominance, and delayed male death. Behav Ecol 17:164-171.

Fisher DO, Owens IPF (2000): Female home range size and the evolution of social organisation in macropod marsupials. J Anim Ecol 69:1093-1098.

Isler K, Van Schaik CP (2009): The expensive brain: a framework for explaining evolutionary changes in brain size. J Hum Evol 57:392400.

Jerison HJ (1973): Evolution of Brain and Intelligence. London, Academic Press.

Kruska DCT (2005): On the evolutionary significance of encephalization in some eutherian mammals: effects of adaptive radiation, domestication, and feralization. Brain Behav Evol 65:73-108.
Myers TJ (2001): Prediction of marsupial body mass. Aust J Zool 49:99-118.

van Dongen PAM (1998): Brain size in vertebrates; in Nieuwenhuys R, ten Donkelaar HJ, Nicholson C (eds): The Central Nervous System of Vertebrates. Berlin, Springer, pp 20992134.

Weisbecker V, Goswami A (2010): Brain size, life history, and metabolism at the marsupial/placental dichotomy. Proc Natl Acad Sci USA 107:16216-16221.

-Weisbecker V, Goswami A (2011): Marsupial brain size indeed confirms ancestral mammalian patterns: a reply to Isler. BioEssays 33: 358-361. 